\title{
CONTRIBUTION OF NUMERICAL THERMAL SIMULATION OF MASONRY TO THE GLOBAL OBJECTIVE OF BUILDINGS ENERGY EFFICIENCY
}

\author{
Hipólito C. Sousa ${ }^{1}$, Rui M. Sousa ${ }^{1}$, Luís C. Silva ${ }^{2}$ and Gonçalo N. Sousa ${ }^{3}$ \\ ${ }^{1}$ Construct - Faculty of Engineering of the University of Porto \\ Rua Dr. Roberto Frias, s/n 4200-465 Porto, Portugal \\ e-mail: hipolito@fe.up.pt, ruysousa@fe.up.pt \\ ${ }^{2}$ Saint-Gobain Weber S.A. - Portugal \\ Zona Industrial de Taboeira 3800-055 Aveiro, Portugal \\ e-mail: Luis.Silva@saint-gobain.com \\ ${ }^{3}$ SOPSEC \\ Rua do Emissor, 110 4400-436 V.N. Gaia, Portugal \\ e-mail: goncalo.sousa@ sopsec.pt
}

Keywords: Energy savings, Lightweight concrete masonry, Thermal performance, Numerical analysis.

\begin{abstract}
The challenge of reduce energy consumption in buildings is fundamental for the near future, considering the impact of buildings in the overall energy needs. Buildings enclosure is a constructive element with a high impact on buildings thermal behavior. Masonry is yet the most popular and used solution to produce buildings external walls. Consequently, the improvement of the thermal resistance of those walls is fundamental. The masonry materials industry, including masonry units, mortars, insulation and finishes is very concerned about this problem, which is complex because there are several constraints namely the wall thickness, enough mechanical resistance and the price.
\end{abstract}

The development of new materials and systems must be very well supported for a good level of knowledge of its behavior, including thermal. Experimental testing in laboratory conditions is expensive for several characteristics and numerical simulations based on the $2 D$ or $3 D$ finite element models are implemented.

In this paper a numerical sensibility analysis of the thermal performance of a new masonry system is presented. This analysis was applied to a lightweight concrete masonry system tested in laboratory in order to evaluate the influence of the thermal properties of the constituent materials. The numerical simulations are based on 3D FE model. The main results are presented and discussed. 


\section{INTRODUCTION}

The reduction of the energy consumption and efficient use of energy in buildings have become increasingly important in recent decades. The growing energy demands caused high impact on the building sector since it is estimated that this sector is responsible for consuming $40 \%$ of the total energy usage in the European Union. In order to reduce this energy consumption the new directive on buildings energy performance [1] established that all buildings constructed after 2018 to 2020 should be nearly zero energy buildings.

To achieve this demanding goal it is necessary to minimize energy consumptions without affecting the thermal comfort requirements. In the case of the construction sector, the performance of the materials/components used in buildings has to be improved, such as enclosure walls with lower thermal transmittance.

Masonry is yet the most popular and used solution used for external/enclosure walls of buildings. Consequently, the reduction of the thermal transmittance of these walls is an important factor to be considered, along with an appropriate combination with the thermal mass, especially in moderate climates and if passive solar design principles are adequately used [2] (building solar orientation and level of shading, surface properties of the glazing elements, amongst others). The masonry materials industry, including masonry units, mortars, insulation and finishes is very concerned about this energy problem, which is complex because there are several constraints to be considered simultaneously, such as the wall thickness, enough mechanical resistance and a competitive price.

Focusing on the reduction of thermal transmittance of masonry, this can be achieved through the use of raw/base materials with lower thermal conductivity and with the use of units whose topology/geometry is conceived to optimize the thermal resistance. For more demanding performances, complementary thermal insulation layers (thermal renderings, external insulation systems) and the filling of the unit voids with thermal insulation materials can also be used, in particular when the increase of wall thickness isn't possible due to practical or economic reasons.

The impact on the energy consumption of building by reducing the thermal transmittance of enclosure walls has been estimated in some scientific studies. For example, according to a numerical study [3] performed on building with four floors and two exposed facades (masonry walls made with vertical hollow units made with thermally enhanced clay) with $33 \%$ of glazing area, annual energy savings near $8 \%$ was estimated, when decreasing the equivalent thermal transmittance of the enclosure walls by $43 \%$.

\section{METHOLOGY}

The main objective of this paper is to study the influence of the thermal properties of the constituent materials on the thermal performance of a new single wall system made with lightweight concrete masonry and thermal enhanced rendering. The thermal properties studied were the thermal conductivity of the base materials, namely 3 new types of lightweight concrete to be used in the units and one thermal enhanced mortar to be used in the bed joints. It is mentioned that this wall system was previously tested in laboratory for other properties that are outside the scope of this paper, such as mechanical resistance of masonry, acoustics behavior and watertightness.

Therefore, the work methodology followed in this study was:

- Experimental determination of the thermal conductivity for the 3 types of concrete used in masonry units (latter to be inserted in the numerical model); 
- Experimental determination of the compressive strength of units made with the 3 types of concrete (to better evaluate the viability of application of these concretes in masonry products)

- Numerical characterization of the thermal performance of the wall system made with masonry units and joints with lower thermal conductivity materials (main focus of the paper), through a 3D FE model calibrated and validated according to a standard methodology and experimental studies;

\section{NUMERICAL SIMULATIONS}

\subsection{Construction aspects of the wall system}

The single-leaf wall system in analysis is to be used as external enclosure/facade of buildings and was considered in this study according to the constructive/detailing provisions given by the manufacturer/producer:

- Masonry unit/block made from lightweight concrete (concrete with a dry density of 1200 $\mathrm{kg} / \mathrm{m}^{3}$ produced with lightweight expanded clay aggregates), vertical perforations (49\%) and with external dimensions of 490x250x190mm (length $\mathrm{x}$ wide $\mathrm{x}$ height), Figure 1;

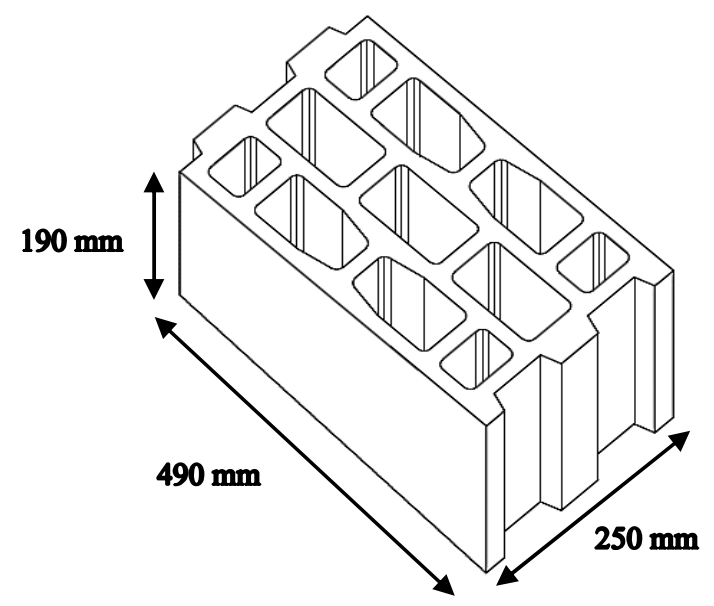

Figure 1: Schematic representation of the masonry unit.

- Vertical joints are interlocking joints (without mortar or dry joints) and bed joints are made with general purpose mortar laid with a central air gap with $65 \mathrm{~mm}$ wide and $10 \mathrm{~mm}$ thick (these bed joints are laid on the blind side of the unit, which is made during the production of the unit with $5 \mathrm{~mm}$ of concrete, thus avoiding mortar penetration into the voids);

- External thermal rendering system applied with $47 \mathrm{~mm}$ of total thickness, i.e., $40 \mathrm{~mm}$ of thermal mortar and $7 \mathrm{~mm}$ of bonding/finishing mortar layers;

- Internal coating/rendering system made with a mineral mortar applied with $20 \mathrm{~mm}$ of total thickness. 


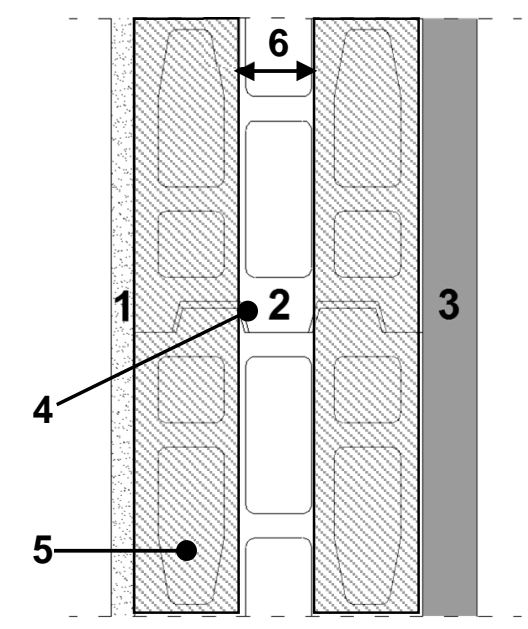

Figure 2: Horizontal cut of the wall system in analysis (1- Internal rendering; 2- Masonry units; 3- External thermal rendering; 4- Shell bedded mortar joints; 5- Dry vertical joints; 6- Central airgap).

\subsection{Thermal properties of the base materials}

Three new types of lightweight concrete (LWC) with different dosages of cement, lightweight expanded clay aggregates, sand and additives were developed by the wall system manufacturer/producer. These new LWC were named in this study according to their dry density $\left(\rho_{\mathrm{g}, \mathrm{dry}}\right)$ :

- LWC670 (lightweight concrete with $670 \mathrm{~kg} / \mathrm{m}^{3}$ );

- LWC810 (lightweight concrete with $810 \mathrm{~kg} / \mathrm{m}^{3}$ );

- LWC1100 (lightweight concrete with $1100 \mathrm{~kg} / \mathrm{m}^{3}$ ).

Laboratory tests were performed according to EN12664 [4] (Guarded hot plate) to determine the thermal conductivity in dry state $\left(\lambda_{10, \text { dry,mat }}\right)$ of these new LWC. Since these types of LWC are molded into masonry units by an industrial vibration/compression process, 6 test samples were cut off directly from units produced in factory conditions ( 2 shells/webs for each type of concrete, Figure 3), therefore reproducing the real manufacturing conditions of the LWC masonry units.

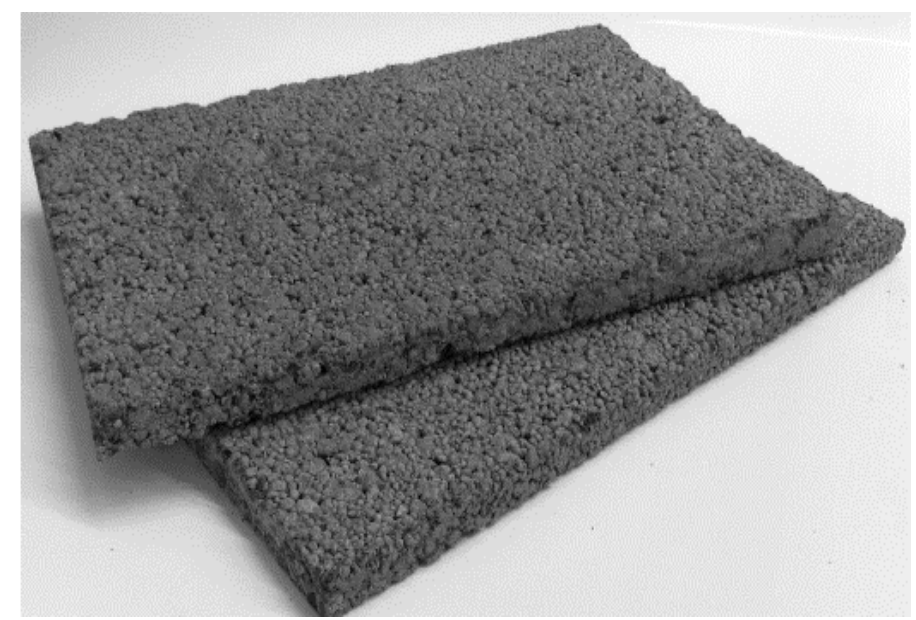

Figure 3: Example of test samples removed from the masonry units (shells/webs). 
Also 2 types of mortar were considered for the bed joints: a thermally improved lightweight mortar and a general purpose mortar (mortar used in the original wall system).

The properties of the base materials used in the joints and in the renderings were given by technical documents provided by the wall system manufacturer.

In order to consider the base materials affected by the moisture content, a design thermal conductivity ( $\left.\lambda_{\text {design,mat }}\right)$ was calculated according to standard methodology (EN 1745 [5] and EN ISO 10456 [6]) for an environment with relative humidity and temperature of $23^{\circ} \mathrm{C}$ and $80 \%$. The results obtained are presented in table 1 and were used in the numerical simulations.

\begin{tabular}{ccccc}
\hline Layer / element & Base material & $\begin{array}{c}\rho_{\mathrm{g}, \mathrm{dry}} \\
\left(\mathrm{kg} / \mathrm{m}^{3}\right)\end{array}$ & $\begin{array}{c}\lambda_{10, \text { dry,mat }} \\
(\mathrm{W} / \mathrm{mK})\end{array}$ & $\begin{array}{c}\lambda_{\text {design,mat }} \\
(\mathrm{W} / \mathrm{mK})\end{array}$ \\
\hline $\begin{array}{c}\text { Internal rendering system } \\
\text { Masonry wall (unit) }\end{array}$ & Meference LW Concrete (LWC1200) & 1500 & 0.610 & 0.775 \\
Masonry wall (unit) & New LW Concrete (LWC1100) & 1100 & 0.410 & 0.462 \\
Masonry wall (unit) & New LW Concrete (LWC 810) & 810 & 0.160 & 0.242 \\
Masonry wall (unit) & New LW Concrete (LWC 670) & 670 & 0.122 & 0.130 \\
Masonry wall (bed joints) & Therm. improved lightweight mortar & 1500 & 0.610 & 0.775 \\
Masonry wall (bed joints) & General purpose mortar & 1800 & 0.930 & 1.182 \\
& Thermal mortar & 150 & 0.042 & 0.053 \\
External thermal render- & Bonding mortar & 1250 & 0.450 & 0.572 \\
ing system & Finishing mortar & 1750 & 0.820 & 1.042 \\
\hline
\end{tabular}

Table 1: Thermal properties of the base materials

For the experimental results obtained its highlighted that the dry thermal conductivity obtained for the new developed LW concretes (LWC1100, LWC810 and LWC670) are lower than the tabulated values given in EN 1745 [5].

\subsection{Mechanical Strength of units}

Laboratory tests were performed according to EN772-1 [7] to determine the compressive strength (perpendicular to the bed joints) of the unit made with the new developed concretes (Figure 4). Only 9 blocks were used ( 3 units per type of concrete) due to the availability of test samples. The final results obtained are succinctly presented on Table 2.
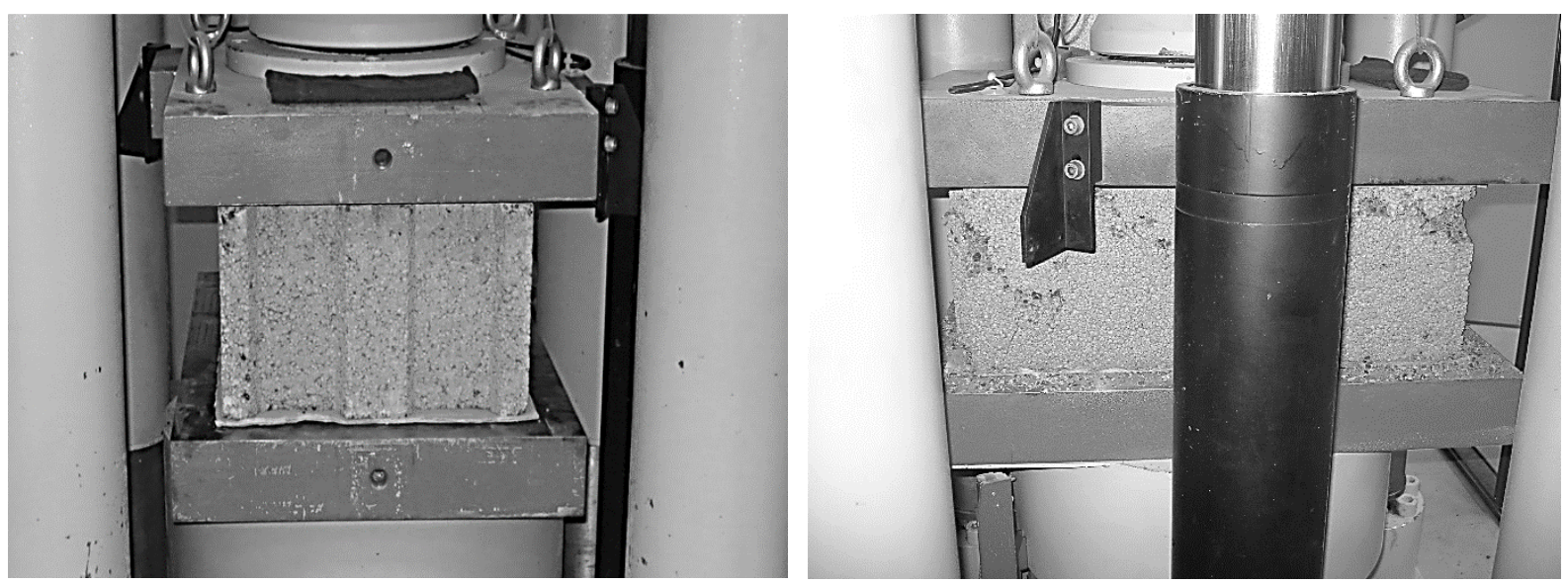

Figure 4: Example of compressive strength tests performed on the masonry units (before and after testing). 


\begin{tabular}{ccc}
\hline $\begin{array}{c}\text { Type of concrete used in the } \\
\text { units/blocks }\end{array}$ & $\begin{array}{c}\text { Average compression } \\
\text { strength }\left(\mathrm{N} / \mathrm{mm}^{2}\right)\end{array}$ & $\begin{array}{c}\text { C.V. } \\
(\%)\end{array}$ \\
\hline LWC670 & 1.4 & 16.6 \\
\hline LWC810 & 2.3 & 16.3 \\
\hline LWC1100 & 3.1 & 5.8 \\
\hline
\end{tabular}

Table 2: Experimental results obtained for the compressive strength of the units

Considering the results obtained, the units made with LWC 810 and LWC1100 concrete has showed the highest compressive strengths, demonstrating viability to have enough mechanical strength to be used as masonry material in real applications (e.g. near the reference limit of 2,5 $\mathrm{N} / \mathrm{mm}^{2}$ defined in a French standard for LWC units to be used in non-structural walls [8]). The unit made with LWC 670 has shown the lowest compressive strength and must be improved.

\subsection{Main aspects of the numerical model}

A micromodel based on FEM was used to simulate the thermal behavior of a wall part, detailing the geometry of the blocks, joints (Figure 5) and rendering/coating layers.

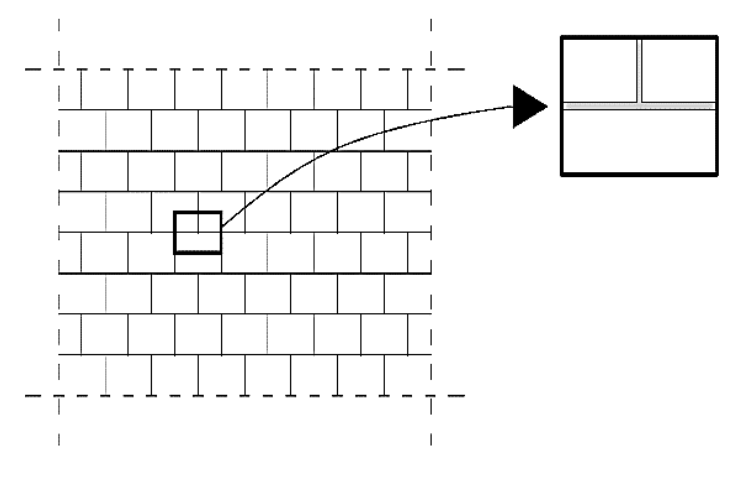

a)

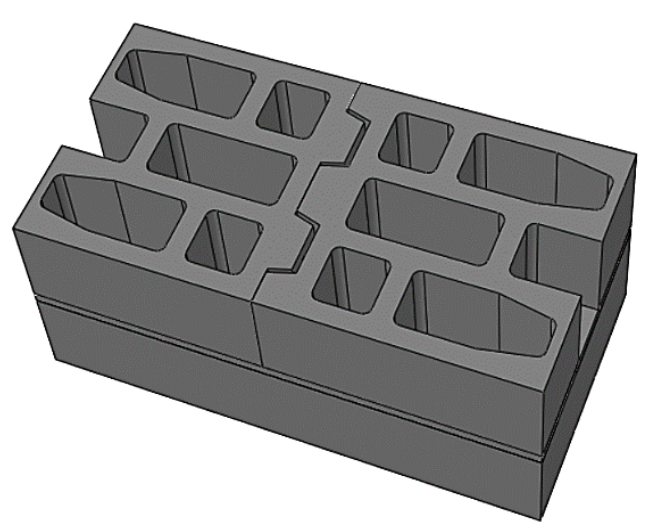

b)

Figure 5: Geometrical model used in thermal simulations (a) Considered part of the masonry wall; b) Detailed $3 \mathrm{D}$ modelling of the masonry wall part).

The simulations were performed by considering a stationary thermal/heat flow obtained from a temperature gradient of $20^{\circ} \mathrm{C}$, the internal and external surface resistances of the wall (Rsi and Rse), the equivalent thermal transmittance of the voids (calculated according to EN ISO 6946[9]), the thermal transmittance of the base materials (see Table 1) and the existence of adiabatic boundaries on the considered part of the wall.

The model accuracy was evaluated and validated according to standards EN 1745[5] e EN ISO 10211[10], i.e., calculation deviations/errors lower than the maximum allowed (1\%) were obtained for heat flux in the simulation of standard reference cases of masonry walls. Moreover, this numerical model was previously used and validated in other scientific studies against experimental results obtained from standard laboratory tests (hot box method using heat flow meters and large wall samples). In these studies the numerical and experimental results obtained exhibited differences near $\pm 4 \%[11,12]$, which are considered acceptable for masonry.

\subsection{Presentation and discussion of results}

As mentioned before, the thermal performance of the wall system was analyzed with the following variations in the masonry base materials: 
- Variation on the type of concrete originally used in masonry units (reference situation), i.e., using units made with the developed concretes (LWC670, LWC810 and LWC1100);

- Variation on the type of mortar originally used in bed joints (reference situation), i.e., using bed joints made with thermally improved lightweight mortar.

This performance was evaluated through the thermal resistance of the masonry in design conditions without renderings ( $\mathrm{R}_{\text {design,mas }}$ ) and through the thermal transmittance of the wall system in design conditions ( $\left.\mathrm{U}_{\text {design}}\right)$. Its highlighted that these design conditions were established by considering that all base materials were affected by moisture content (see 3.2) and had no ageing effects nor other environmental attacks (initial conditions of use were considered). The obtained results are presented in Table 3.

\begin{tabular}{|c|c|c|c|c|}
\hline \multirow{3}{*}{$\begin{array}{l}\text { Type of con- } \\
\text { crete used in the } \\
\text { units/blocks }\end{array}$} & $\begin{array}{l}\text { Design ther } \\
\text { sonry withou }\end{array}$ & $\begin{array}{l}\text { ign, mas } \\
\text { resistance of ma- } \\
\text { nderings }\left(\mathrm{m}^{2} \mathrm{~K} / \mathrm{W}\right)\end{array}$ & \multicolumn{2}{|c|}{$\begin{array}{c}\text { Design thermal transmittance of the } \\
\text { wall system }\left(\mathrm{W} / \mathrm{m}^{2} \mathrm{~K}\right)\end{array}$} \\
\hline & \multicolumn{2}{|c|}{ Bed joint mortar } & \multicolumn{2}{|c|}{ Bed joint mortar } \\
\hline & $\begin{array}{l}\text { Lightweight } \\
\text { improved }\end{array}$ & $\begin{array}{l}\text { General purpose } \\
\text { (reference) }\end{array}$ & $\begin{array}{l}\text { Lightweight } \\
\text { improved }\end{array}$ & $\begin{array}{l}\text { General purpose } \\
\text { (reference) }\end{array}$ \\
\hline LWC670 & 1.29 & 1.21 & 0.44 & 0.46 \\
\hline LWC810 & 1.12 & 1.06 & 0.48 & 0.50 \\
\hline LWC1100 & 0.98 & 0.94 & 0.52 & 0.53 \\
\hline $\begin{array}{l}\text { LWC1200 } \\
\text { (reference) }\end{array}$ & 0.73 & 0.70 & 0.60 & 0.60 \\
\hline
\end{tabular}

Table 3: Results obtained in numerical simulations

An example of the thermal/heat flow distribution obtained for masonry walls is presented in Figure 6 and the thermal transmittance in design conditions $\left(\mathrm{U}_{\text {design }}\right)$ of the wall system is presented in Figure 7 according to the type of concrete and type of mortar joints.

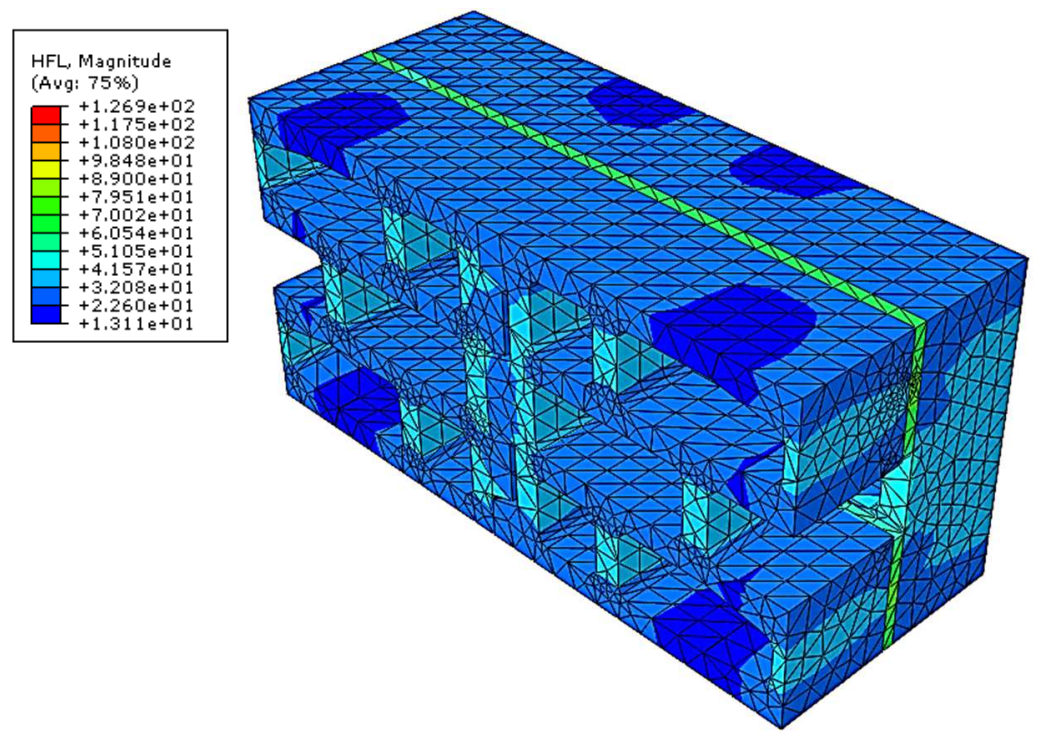

Figure 6: Example of the heat flow in the masonry wall (without renderings) 


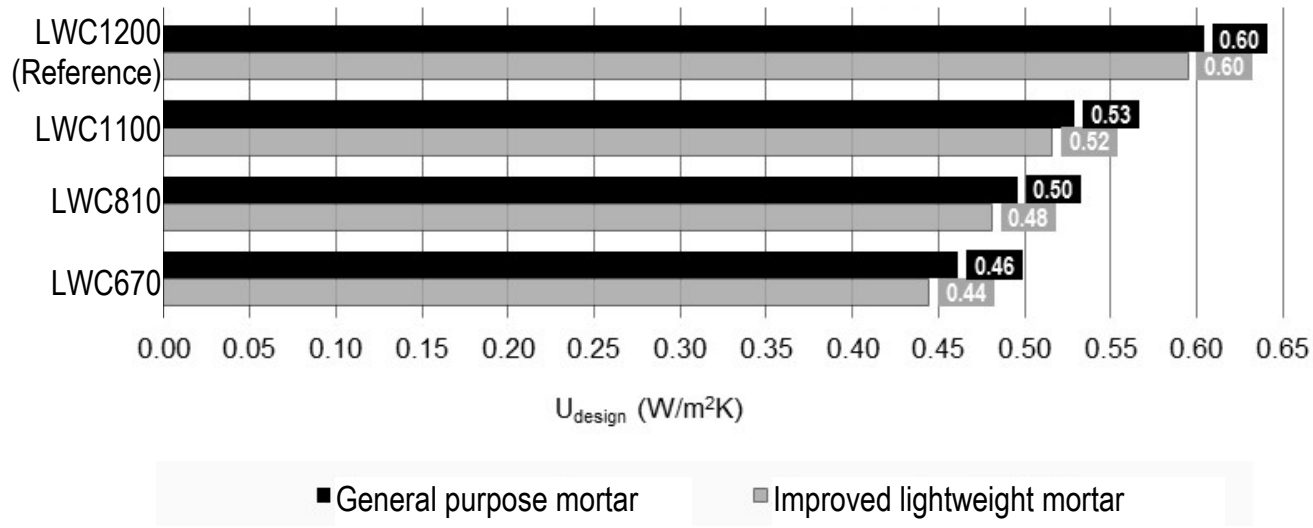

Figure 7: Design thermal transmittance obtained for the wall system made with different base materials

From the obtained results the following aspects are highlighted:

- The units made with the new lightweight concretes (LWC670, LWC810 and LWC1100) improved the thermal resistance of masonry (increase of 34 to 77\%) and the thermal transmittance of the wall systems (decrease of $12 \%$ a $27 \%$ ), although in last case with lower impact due to the use of external rendering system with high thermal insulation capability; Moreover, this improvement is higher when using both mortar joints and units with the highest thermal resistances;

- The use of bed joints made with thermally improved mortar only had slight improvement on the masonry thermal resistance (increase of 4 to $7 \%$ ) or on the thermal transmittance of the wall systems (reduction of almost 0 to $4 \%$ ), since there is a low quantity of mortar applied on the masonry joints (use of discontinuous and dry joints). Nevertheless, this slight improvement is higher when using both mortar joints and units with the highest thermal resistances;

\section{GENERAL CONCLUSIONS}

The experimental results revealed the development of new lightweight concretes with a lower thermal conductivity and enough mechanical strength to be used in masonry applications, in particular for the LWC810 and LWC1100 concretes. However, the LWC670 concrete should be improved given the lower mechanical strength obtained.

The numerical simulations demonstrated that the use of these concretes on the units, together with the use of thermal enhanced mortar in the bed joints, can significantly reduce the thermal transmittance of the wall system.

Therefore, the use of these new lightweight concretes in masonry applications, especially in the case of LWC810 and LWC1100, have a high potential to produce units and walls systems with enough mechanical strength and lower thermal transmittance, the latter contributing for the reduction of energy consumption of buildings.

\section{ACKNOWLEDGEMENTS}

The authors gratefully acknowledge Saint-Gobain Weber S.A. - Portugal for the funding and support provided in the realization of this study.

\section{REFERENCES}


[1] EBPD 2010 - Directive 2010/31/EU of the European Parliament and of the Council of 19th May 2010 on Energy Performance of Buildings (recast).

[2] D. Alterman, A.W. Page, T. Moffiet, B. Moghtaderi, A measure for the dynamic thermal performance of walling systems incorporating the combined effect of thermal mass and thermal resistance. 9th International Masonry Conference $\left(9^{\text {th }} I M C\right)$, Guimarães, Portugal, July 7-9, 2014.

[3] M. Morales, P. Muñoz, M. Juárez, M. Mendívil, L. Muñoz, Energy efficiency in buildings: Study of single-leaf walls made with clay bricks. Journal of Energy Engineering, 142 (1), 2016.

[4] CEN, EN-12664 - Thermal performance of building materials and products: Determination of thermal resistance by means of guarded hot plate and heat flow meter methods Dry and moist products of medium and low thermal resistance. Brussels, 2001.

[5] CEN, EN 1745 - Masonry and masonry products: Methods for determining thermal properties. Brussels, 2012.

[6] CEN, EN ISO 10456 - Building materials and products: Hygrothermal properties - Tabulated design values and procedures for determining declared and design thermal values. Brussels, 2007.

[7] VEN, EN772-1 - Methods of test for masonry units: Part 1 - Determination of compressive strength. Brussels, 2011.

[8] CSTB, NF P14 304 - Agglomérés - Blocs en béton de granulats légers pour murs et cloisons. Paris, 1983.

[9] CEN, EN ISO 6946 - Building components and building elements: Thermal resistance and thermal transmittance - Calculation method. Brussels, 2007.

[10] CEN, EN ISO 10211. Thermal bridges in building construction; Heat flows and surface temperatures; Detailed calculations. Brussels, 2007.

[11] H. Sousa, R. Sousa, Sensibility analysis of the thermal resistance of masonry through numerical simulations of laboratory tests. 9th International Masonry Conference Guimarães ( $\left.9^{\text {th }} I M C\right)$, Guimarães, Portugal, July 7-9, 2014.

[12] N. Ramos, V.P. Freitas, P. Pereira, H. Sousa, R. Sousa, U-value determination of masonry walls with complex shape units and thermal rendering. 10th Nordic Symposium on Building Physics (10 ${ }^{\text {th }}$ NSB), Lund City Centre, Sweden, June 15-19, 2014. 